\title{
Gastroenterite Aguda por Campylobacter Spp: Casuística de uma Urgência Pediátrica
}

\author{
Acute Gastroenteritis by Campylobacter Spp: a Retrospective Study of a \\ Paediatric Emergency Department
}

\author{
Ana Teresa SOARES ${ }^{1}$, Catarina COUTO ${ }^{1}$, Patrícia ROMÃO², Isabel Saraiva de MELOㄹ, Manuela BRAGA ${ }^{1}$, José \\ DIOGO 3 , Paulo CALHAU ${ }^{1}$ \\ Acta Med Port 2014 Sep-Oct;27(5):556-560
}

\section{RESUMO}

Introdução: A infeção por Campylobacter é a principal causa de gastroenterite aguda bacteriana pediátrica na União Europeia.

Objetivos: Conhecer a prevalência de isolamento deste agente nas crianças admitidas na urgência com gastroenterite aguda que realizaram coprocultura, caracterizando a microbiologia, epidemiologia, clínica, terapêutica e complicações associadas.

Material e Métodos: Casuística por consulta dos processos dos doentes admitidos na Urgência Pediátrica dum hospital distrital, durante 30 meses, com o diagnóstico de gastroenterite aguda e isolamento em coprocultura de Campylobacter.

Resultados: Das 216 coproculturas efetuadas, 98 (45\%) foram positivas. Identificámos Campylobacter spp. em 49 (50\%) doentes. Destes, $30(61 \%)$ eram do género feminino. A mediana de idades foi 23 meses. Catorze doentes tinham idade inferior a um ano, 25 entre um e cinco anos e 10 idade superior a cinco anos. Verificámos diarreia aquosa em cinco (10\%) doentes, diarreia com sangue em 44 (90\%), sangue e muco em 14 (29\%), febre em 23 (47\%), dor abdominal em 14 (29\%) e vómitos em 11 (22\%). Registámos um caso de sépsis. Internámos cinco doentes. Oito doentes foram medicados com azitromicina.

Discussão: Esta é a maior casuística nacional publicada de gastroenterite aguda a Campylobacter em idade pediátrica e a primeira no sul do país. Campylobacter foi a principal bactéria identificada, associada maioritariamente a doença auto-limitada. Contudo, há a considerar formas de infeção graves. $\mathrm{O}$ aumento da resistência às quinolonas é preocupante.

Conclusão: A utilização criteriosa da coprocultura permite a identificação etiológica na gastrenterite aguda bacteriana. $\mathrm{O}$ crescente aumento dos casos de Campylobacter diagnosticados reforça a necessidade de maior controlo das medidas de higiene na manipulação dos alimentos.

Palavras-chave: Campylobacter; Criança; Gastroenterite; Infecções por Campylobacter; Serviço de Urgência Hospitalar; Portugal.

\section{ABSTRACT}

Introduction: Infection by Cambylobacter occurs worldwide and represents the main cause of acute bacterial gastroenteritis within the European Union.

Aims: Determine the prevalence of Campylobacter in stool cultures from patients with gastroenteritis and study their microbiological, epidemiological, clinical, and therapeutic profiles, as well as associated complications.

Material and Methods: Review of clinical files of patients presenting to the paediatric emergency department of a general district hospital over a 30 month period with an acute gastroenteritis and a Campylobacter isolated in a stool specimen.

Results: Out of 216 stool cultures, 98 (45\%) were positive. We identified Campylobacter in $49(50 \%)$ cases; 30 (61\%) were female. Median age was 23 months. Fourteen patients were under one year of age, 25 between one and five years old and 10 patients were over five years old. Watery diarrhea was identified in $5(10 \%)$ patients, bloody diarrhea in $44(90 \%)$ and mucosanguineous in $14(29 \%)$, while $23(47 \%)$ had fever, $14(29 \%)$ complained of abdominal pain and $11(22 \%)$ presented with vomiting. One patient was septic. Five patients were admitted as inpatients. Eight patients were treated with azithromycin.

Discussion: This is the largest published national series on gastroenteritis by Campylobacter in children and the first in the south region. Campylobacter was the main bacteria isolated. Infection was self-resolving in the majority of cases. Nevertheless, severe forms of this infection should be considered. Increased resistance to quinolones is worrisome.

Conclusion: Judicious use of stool cultures allows etiological identification of bacterial gastroenteritis. The increase in Campylobacter cases reinforces the need for better control of hygiene measures in handling food products.

Keywords: Campylobacter; Child; Gastroenteritis; Campylobacter Infections; Emergency Service, Hospital; Portugal.

\section{INTRODUÇÃO}

A infeção por Campylobacter spp. apresenta uma distribuição mundial, ${ }^{1,2}$ sendo a principal causa de gastroenterite aguda (GEA) bacteriana em pediatria na União Europeia, com uma prevalência superior à infeção causada por Salmonella spp., Shigella spp. e Escherichia coli enteropatogénica. ${ }^{3,4}$ Nos últimos anos, tem-se verificado um aumento significativo do número de casos de GEA a Campylobacter spp. diagnosticados na Europa. ${ }^{3,5,6}$ No que respeita à prevalência em Portugal, dados recentes referem um crescente número de casos confirmados nos últimos anos. Verificou-se uma maior prevalência no grupo etário entre um e cinco anos, bem como um número significativo em recém-nascidos e lactentes, sendo Campylobacter jejuni a espécie mais frequentemente identificada. ${ }^{5}$

Embora já tenham sido identificadas mais de 20 espécies, Campylobacter jejuni e Campylobacter coli são as

\footnotetext{
1. Serviço de Pediatria. Hospital Garcia de Orta. Almada. Portugal.

2. Departamento de Pediatria. Hospital de Santa Maria. Centro Hospitalar Lisboa Norte. Lisboa. Portugal.

3. Serviço de Patologia Clínica. Laboratório de Microbiologia. Hospital Garcia de Orta. Almada. Portugal.
}

Recebido: 30 de Dezembro de 2013 - Aceite: 19 de Maio de 2014 | Copyright $\odot$ Ordem dos Médicos 2014 
mais frequentemente envolvidas na infeção humana. ${ }^{1,5,6}$ No que respeita aos mecanismos patogénicos envolvidos na GEA, pensa-se que a bactéria lesa as células epiteliais intestinais por invasão direta, por indução de um processo inflamatório e pela produção de uma toxina. . $^{1,69,12,13}$

Está habitualmente associado a um reservatório animal (aves, gado bovino, caprino e ovino) e transmite-se maioritariamente pela ingestão de carne mal cozinhada (principalmente de aves), leite não pasteurizado, outros alimentos

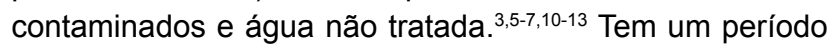
de incubação entre dois a cinco dias. ${ }^{3,6,9}$

Do quadro clínico, destaca-se a diarreia aguda aquosa, com sangue e/ou muco associada a sintomas sistémicos como febre, vómitos, dor abdominal e cefaleias. Na maioria dos casos, particularmente em crianças saudáveis, constitui uma doença auto-limitada, embora estejam descritas complicações tais como artrite reativa, sépsis, síndrome de Guillain-Barré, anemia hemolítica, entre outras. . $^{3,5-7,11-14}$

O diagnóstico é habitualmente feito por isolamento da bactéria em coprocultura e identificação por galeria de identificação bioquímica, espectrometria de massa ou métodos moleculares. Pode ainda ser complementada por exame microscópico direto das fezes, microscopia de campo escuro, deteção de antigénio específico, identificação do ADN da bactéria por técnicas de Polymerase Chain Reaction (PCR) e ainda por serologia por técnica de ELISA., ${ }^{7,8,11,13}$

$\mathrm{Na}$ maioria dos casos o tratamento consiste na reposição hidroelectrolítica oral. A terapêutica antimicrobiana está recomendada em casos selecionados: diarreia com sangue, sintomas com duração superior a uma semana, febre alta, doença extra-intestinal, GEA em doentes imunodeprimidos ou em doentes com patologia crónica e situações de surto. Os fármacos de primeira linha são os macrólidos. ${ }^{1,6,8}$

Os objetivos do presente estudo foram: 1) conhecer a prevalência de isolamento de Campylobacter spp. nos doentes admitidos numa urgência pediátrica com diagnóstico de GEA e que realizaram coprocultura 2) caracterizar estes casos do ponto de vista microbiológico, epidemiológico, clínico e atitude terapêutica e 3) averiguar complicações associadas.

\section{MATERIAL E MÉTODOS}

Revisão casuística, realizada por consulta dos processos clínicos dos doentes admitidos na Urgência Pediátrica de um hospital distrital entre Janeiro de 2011 e Junho de 2013 (30 meses) com idade inferior a 15 anos.

Incluímos doentes com diagnóstico de GEA que realizaram coprocultura na qual foi isolado Campylobacter spp. O diagnóstico microbiológico foi obtido através da cultura das fezes em meio seletivo para Campylobacter spp. (columbia agar suplementado com sangue de carneiro e com quatro antimicrobianos: cefaperazona, vancomicina, colistina e anfotericina B) com incubação em atmosfera de microaerofilia a $42^{\circ} \mathrm{C}$ durante 48 horas. A identificação das bactérias foi efetuada por espectrometria de massa tipo MALDI-TOF através da determinação do peso molecular de fragmentos proteicos ribossómicos específicos. As amostras foram enviadas para o laboratório de referência, Laboratório Nacional de Referência das Infeções Gastrintestinais, INSA, onde foram estudadas as resistências de um subgrupo de estirpes selecionadas aleatoriamente de entre todas as que foram recebidas provenientes de diversas instituições. Para realização do Teste de Sensibilidade ao Antibiótico (TSA), o método utilizado foi a difusão em disco, em meio Mueller-Hinton suplementado com $5 \%$ de sangue desfibrinado de cavalo e $20 \mathrm{mg} / \mathrm{L}$ de beta-NAD. A incubação foi feita a $37^{\circ} \mathrm{C}$, durante 24 horas em microaerofilia. Os discos tinham as seguintes cargas de antibiótico: ciprofloxacina $5 \mathrm{mcg}$, tetraciclina $30 \mathrm{mcg}$, eritromicina $15 \mathrm{mcg}$ e gentamicina $10 \mathrm{mcg}$. As estirpes foram categorizadas segundo os cut-offs do EUCAST 2014.

Recolhemos dados demográficos (idade, género), epidemiológicos (outros casos na família, ingestão de carne de aves), clínicos (número de dejeções, características das fezes, presença de outros sintomas), referentes a complicações associadas e terapêutica efetuada.

Constitui prática habitual na Urgência Pediátrica do nosso hospital efetuar coprocultura aos doentes com gastroenterite que se apresentem com diarreia prolongada, diarreia com sangue e/ou muco, febre elevada, doentes com patologia crónica, imunodeprimidos e doentes internados.

\section{RESULTADOS}

Durante o período de estudo admitimos na Urgência Pediátrica um total de 6.242 doentes com o diagnóstico de gastroenterite aguda. Foram realizadas 216 coproculturas $(3,5 \%)$, das quais $98(45 \%)$ foram positivas. Identificámos Campylobacter spp. em 49 casos (50\%), seguido da Salmonella em 27 (28\%), Yersinia enterocolitica em dez (10\%), Aeromonas spp. em nove (9\%) e Escherichia coli 0157 em três (3\%) (Fig. 1). Relativamente ao género Campylobacter, Campylobacter jejuni foi a principal espécie identificada, em 48 casos (98\%), seguido do Campylobacter coli, num único caso $(2 \%)$.

Dos 49 doentes com isolamento em coprocultura de Campylobacter spp., 30 (61\%) eram do género feminino. A mediana de idades foi 23 meses (mínimo de um mês e seis dias, máximo de 12 anos).

No que respeita à distribuição por grupos etários, registámos 14 casos no grupo com idade inferior a um ano, 25 no grupo entre um e cinco anos e 10 casos em crianças com idade superior a cinco anos (Fig. 2).

Verificámos um aumento do número de casos diagnosticados ao longo do período do estudo, com 11 casos em 2011, 24 em 2012 e 14 no primeiro semestre de 2013 (Fig. 3). Em 2011 e 2012 constatámos maior número de coproculturas positivas para este género no primeiro semestre do ano comparativamente ao segundo $(n=21,68 \%$ versus $n=14,32 \%)$.

As formas de apresentação incluíram: diarreia aquosa ( $n=5,10 \%)$; diarreia com sangue $(n=44,90 \%)$, diarreia com sangue e muco $(n=14,29 \%)$; febre $(n=23,47 \%)$; dor abdominal ( $n=14,29 \%)$; vómitos ( $n=11,22 \%)$ e exantema $(n=2,4 \%)$. No primeiro ano de vida, quatro doentes 


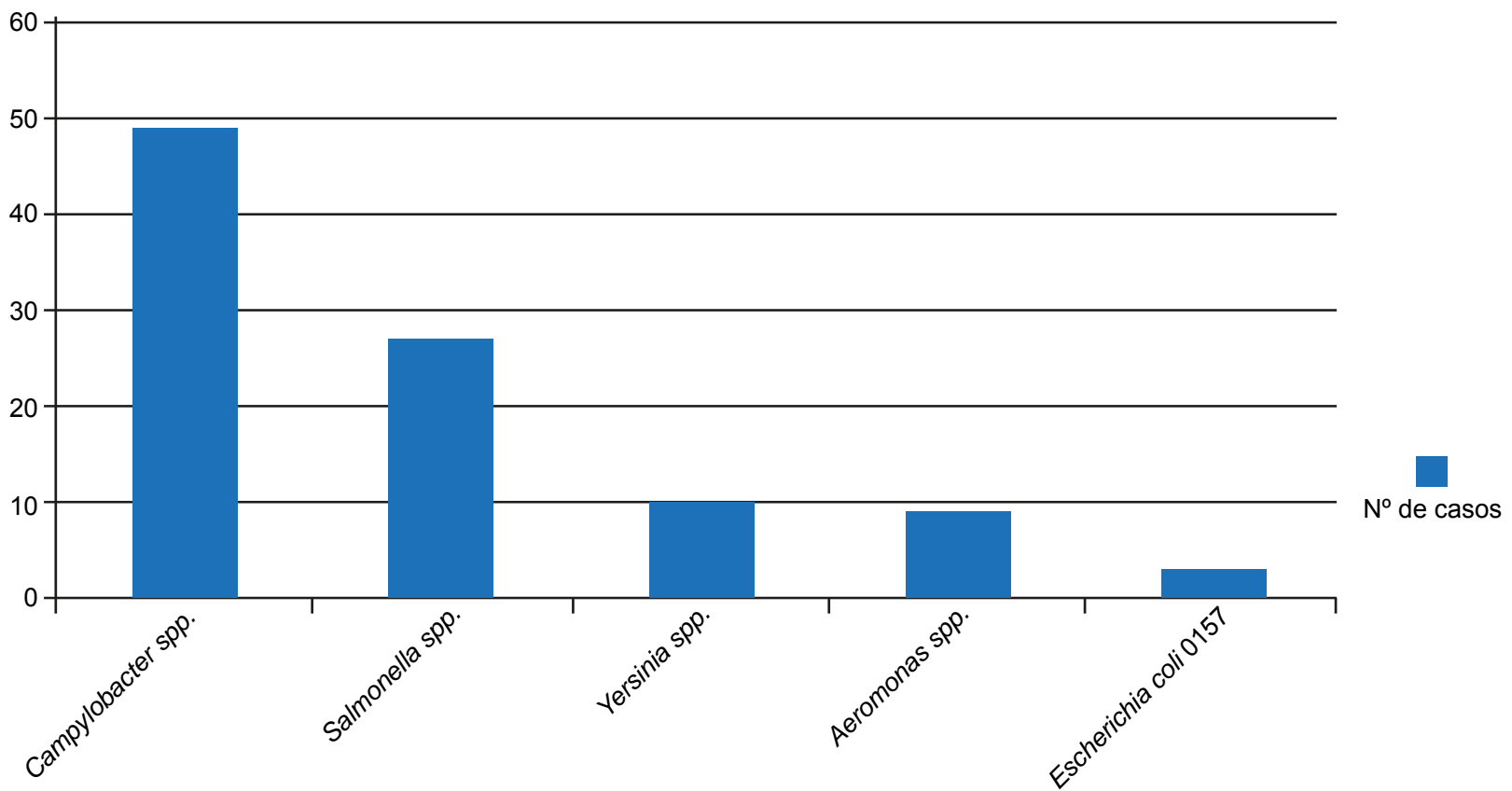

Figura 1 - Bactérias identificadas

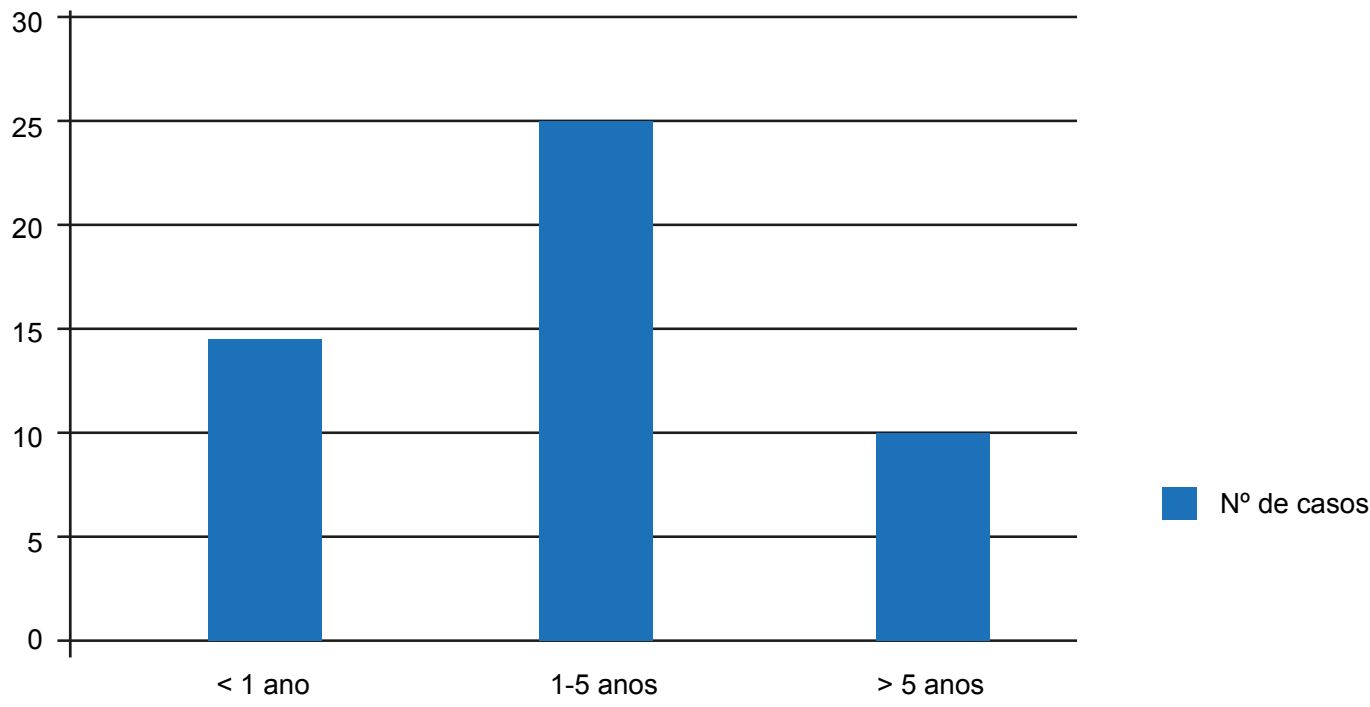

Figura 2 - Gastroenterite aguda por Campylobacter spp. nos diferentes grupos etários.

apresentaram-se com febre; acima de um ano tiveram febre 19 (54\%) crianças (Tabela 1). Internámos cinco doentes (10\%), três dos quais com idade inferior a um ano, com uma duração média de internamento de 1,8 dias. Duas crianças foram submetidas a hidratação endovenosa. Destacamos um caso de sépsis numa criança de um mês.

Readmitimos na urgência 18 crianças (37\%) por diarreia prolongada e com sangue.

No laboratório de referência foram selecionados aleatoriamente 18 amostras para análise (37\% do grupo estudado) para estudo do padrão de resistência aos antibióticos. Verificámos $88 \%$ de resistência às quinolonas, $61 \%$ às tetraciclinas e $22 \%$ aos macrólidos; não registámos nenhum caso de resistência aos aminoglicosídeos. Quanto à tera- pêutica, medicámos oito doentes com azitromicina oral, por diarreia prolongada com sangue.

\section{DISCUSSÃO}

A GEA é uma patologia comum em pediatria, habitualmente com um curso clínico benigno e auto-limitado. A sua origem é viral na maioria dos casos, no entanto a prevalência da etiologia bacteriana é significativa. ${ }^{4,15,16}$

$\mathrm{Na}$ nossa casuística, Campylobacter spp. foi a principal bactéria isolada em $50 \%$ das coproculturas positivas. Existem dois estudos nacionais em idade pediátrica com metodologia semelhante ao nosso: um realizado em 2005 na região Centro, também em meio urbano e que apresenta resultados semelhantes aos nossos; ${ }^{11}$ outro de 2006 


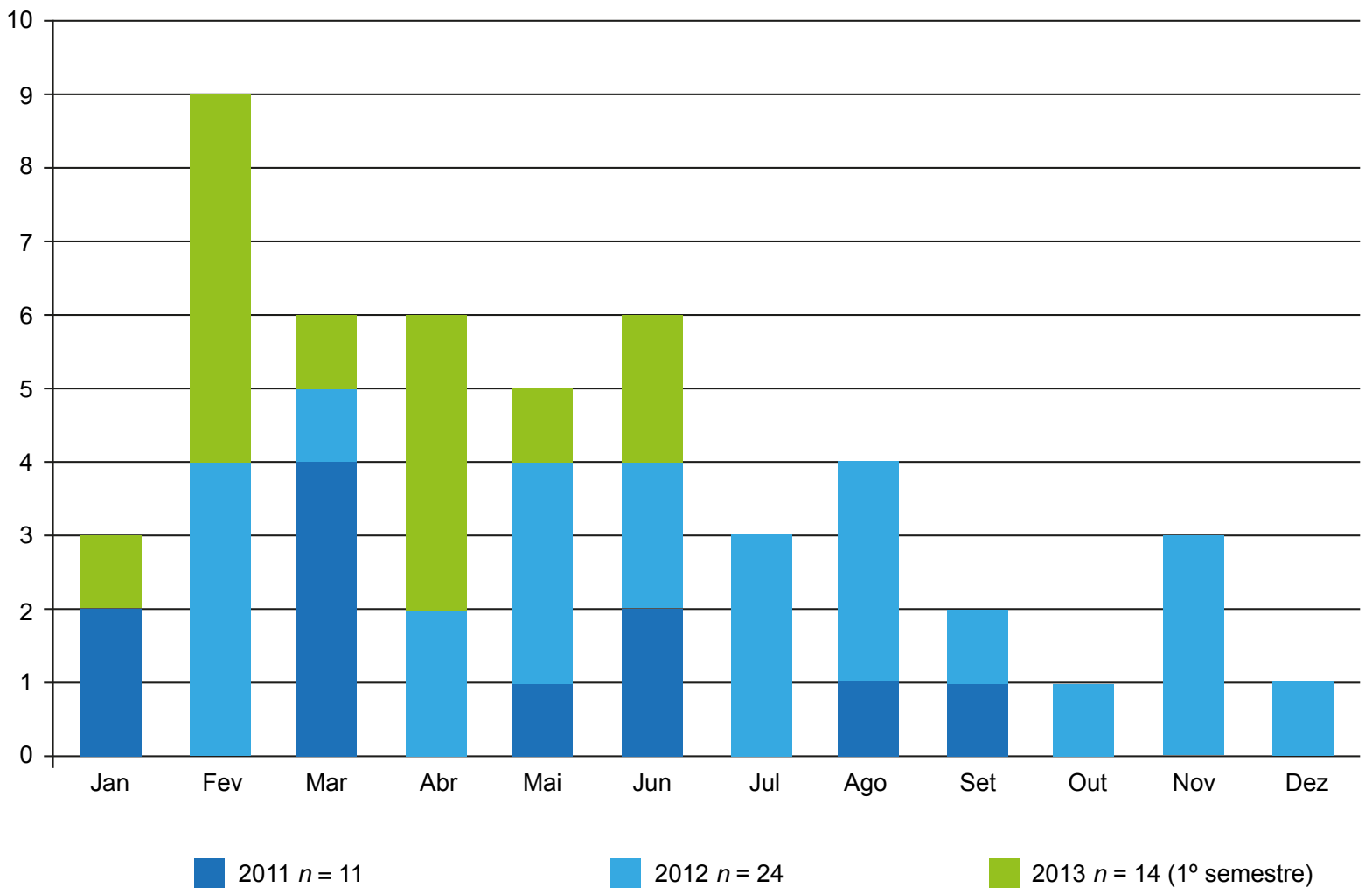

Figura 3 - Número de casos diagnosticados ao longo dos meses

Tabela 1 - Sintomas associados a Gastroenterite aguda por Campylobacter spp

\begin{tabular}{|c|c|c|c|}
\hline Clínica & $\begin{array}{c}\text { Total amostra } \\
n=49 \\
n(\%)\end{array}$ & $\begin{array}{c}\text { Idade }<1 \text { ano } \\
n=14(n)\end{array}$ & $\begin{array}{c}\text { Idade } \geq 1 \text { ano } \\
n=35(n)\end{array}$ \\
\hline \multicolumn{4}{|l|}{ Diarreia } \\
\hline Aquosa & $5(10 \%)$ & 2 & 3 \\
\hline Sangue & $44(90 \%)$ & 12 & 32 \\
\hline Muco & $14(29 \%)$ & 4 & 10 \\
\hline Febre & $23(47 \%)$ & 4 & 19 \\
\hline Dor abdominal & $14(29 \%)$ & 0 & 14 \\
\hline Vómitos & $11(22 \%)$ & 3 & 8 \\
\hline Exantema & $2(4 \%)$ & 1 & 1 \\
\hline
\end{tabular}

também na região Centro, mas abrangendo os meios urbano e rural, no qual Salmonella spp foi o agente mais frequente (54\% das coproculturas positivas) seguido de Campylobacter spp (23\%). ${ }^{14}$ Noutro estudo mais recente de 2013, efetuado na região de Lisboa, a Escherichia coli foi o agente bacteriano mais frequente $(43 \%)$, seguido de Campylobacter spp (37\%); no entanto, é um estudo realizado apenas em doentes internados e como tal os resultados não poderão ser comparados. ${ }^{17}$

No que respeita às diferentes espécies de Campylobacter, Campylobacter jejuni foi a mais frequentemente envolvida nos casos de GEA, com um aumento do número de casos diagnosticados ao longo dos anos, tal como tem sido demonstrado noutros estudos. ${ }^{3,5}$

Verificámos um maior número de casos em crianças com idades compreendidas entre um e cinco anos. Identificámos um número elevado de casos abaixo de um ano de idade, à semelhança do que consta no relatório nacional recentemente publicado 4 e num dos estudos nacionais já referido. ${ }^{14}$ Já no estudo realizado em doentes internados, ${ }^{17}$ esta bactéria foi mais frequentemente isolada em doentes acima dos 12 meses e particularmente acima dos cinco anos de idade. Contudo, trata-se de uma amostra de pequena dimensão e referente a doentes internados, por isso com características clínicas diferentes da nossa.

No que respeita às manifestações clínicas, também estas foram sobreponíveis às apresentadas num dos estudos nacionais. ${ }^{14}$

A forma de apresentação no primeiro ano de vida foi semelhante à dos restantes grupos etários; destacamos, 
contudo um caso de sépsis num lactente de um mês.

A elevada frequência de casos de diarreia com sangue ou muco no grupo estudado poderá refletir a prática clínica e os critérios para realização de coprocultura praticados no nosso hospital. Segundo dados da literatura, cerca de metade dos casos cursam com diarreia aquosa e não diarreia com sangue como evidenciado na nossa casuística. ${ }^{3,8,13}$

Embora importante do ponto de vista epidemiológico, a investigação etiológica está recomendada nos casos em que se preconiza terapêutica dirigida: situações de surto, diarreia com sangue e/ou muco, sintomas com duração superior a uma semana, febre alta, doença extra-intestinal, doentes imunodeprimidos, doentes com patologia crónica, doentes provenientes de países tropicais ou como auxiliar de diagnóstico diferencial. ${ }^{4} \mathrm{~A}$ taxa de isolamento nas coproculturas realizadas no nosso estudo foi de $45 \%$, enquanto que nos estudos referidos foi entre 21 e $36 \% .^{11,14,17}$

$\mathrm{Na}$ amostra de casos em que foi realizada o TSA verificámos um padrão de resistência aos antibióticos semeIhante ao descrito na literatura, embora com uma maior taxa de resistência às quinolonas. Este último dado é corroborado pelo aumento progressivo da taxa de resistência às quinolonas, nos últimos anos, demonstrada em diversos estudos, sendo um dado preocupante do ponto de vista epidemiológico. ${ }^{2,8,9}$

Tal como está recomendado, prescrevemos tratamento antimicrobiano em casos selecionados. Na nossa série, apenas oito doentes foram medicados com azitromicina oral durante cinco dias, por diarreia com sangue prolongada.

Destacamos que apenas cinco doentes (10\%) foram internados e que dois fizeram hidratação endovenosa, ao contrário de outro estudo nacional onde o número de doentes com necessidade de internamento foi consideravelmente superior. ${ }^{11}$

No momento da alta da urgência, foram explicados aos

\section{REFERÊNCIAS}

1. Heresi GP, Murphy JR, Cleary TG. Campylobacter jejuni. In: Feigin RD, Cherry JD, Demmler-Harrioson GJ, Kaplan SL, editors. Feigin and Cherry's textbook of pediatric infectious diseases. Philadelphia: Saunders Elsevier; 2009. p. 1612-8.

2. Lengerh A, Moges F, Unakal C, Anagaw B. Prevalence, associated risk factors and antimicrobial susceptibility pattern of Campylobacter species among under five diarrheic children at Gondar University Hospital, Northwest Ethiopia. BMC Ped. 2013;13:82.

3. EFSA (European Food Safety Authority), ECDC (European Centre for Disease Prevention and Control). The European Union summary report on trends and sources of zoonoses, zoonotic agents and food-borne outbreaks in 2011. EFSA J. 2013;11:3129-250.

4. Guarino A, Albano F, Ashkenazi S, Gendrel D, Hoekstra JH, Shamir R, et al. European Society for Paediatric Gastroenterology, Hepatology, and Nutrition/European Society for Paediatric Infectious Diseases evidencebased guidelines for the management of acute gastroenteritis in children in Europe. J Pediatr Gastroenterol Nutr. 2008;46:S81-122.

5. Duarte A, Santos A, Benoliel J, Domingues F, Oleastro M. A infeção humana por Campylobacter em Portugal: alguns dados epidemiológicos. Instituto Nacional de Saúde Doutor Ricardo Jorge. Infeções Gastrointestinais. Artigos breves No.7. 2013.

6. Heresi GP, Baqar S, Murphy JR. Campylobacter. In: Kliegman RM, Stanton BF, Schor NF, Geme JW, Behrman RE, editors. Nelson Textbook of Pediatrics. Philadelphia: Elsevier Saunders; 2011. p. 968-70.

7. Tamborini AL, Casabona LM, Viñas MR, Asato V, Hoffer A, Farace MI, et al. Campylobacter spp.:prevalência y caracterización feno-genotípica cuidadores os sinais de alarme a vigiar e sempre que necessário procedemos à reavaliação dos doentes. Consideramos que a evolução clínica foi de um modo geral favorável, traduzida pelo reduzido número de complicações e baixa taxa de internamento.

Por se tratar de um estudo retrospetivo não foi possível, por falta de registo, identificar a provável fonte de infeção nem a presença de outros casos na família.

\section{CONCLUSÃO}

A infeção por Campylobacter spp. é a principal causa de GEA bacteriana na União Europeia. Nos últimos anos, tem-se verificado um aumento do número de novos casos diagnosticados, por razões ainda por esclarecer. Apesar de na maioria dos casos se tratar de uma doença auto-limitada e com uma evolução clínica favorável, há que ter em conta a existência de complicações associadas e de outras formas de infeção mais graves e potencialmente fatais. A coprocultura permite a identificação etiológica, fundamental nas situações em que se preconize terapêutica dirigida.

O aumento do número de casos diagnosticados ao longo dos anos sugere a necessidade de um maior incentivo e sensibilização, em sede de cuidados de saúde primários, para as adequadas medidas de higiene na manipulação e preparação dos alimentos.

Atualmente, esta é a maior casuística nacional em idade pediátrica de GEA por Campylobacter spp. e a primeira no sul do país.

\section{CONFLITOS DE INTERESSE}

Os autores declaram não existir conflitos de interesse.

\section{FONTES DE FINANCIAMENTO}

Os autores declaram que não existiu qualquer apoio financeiro.

de aislamientos de pacientes com diarrea y sus mascotas en la provincia de La Pampa, Argentina. Rev Argent Microbiol. 2012;44:266-71.

8. Adedayo O, Kirkpatrick BD. Campylobacter jejuni infections: update on presentation, diagnosis, and management. Hosp Physician. 2008;44:915.

9. Crushell E, Harty S, Sharif F, Bourke B. Enteric Campylobacter: purging its secrets? Pediatr Res. 2004;55:1.

10. Sellu DP. Campylobacter enterocoloitis: general and surgical aspects. Postgrad Med J. 1986;62:719-26.

11. Borges AC, Pedrosa C, Santos A, Vitorino M, Costa M, Godinho C Campylobacter jejuni: gastrenterites agudas e infecções extra-intestinais. Acta Pediatr Port. 2005;36:191-3.

12. Ketley JM. Pathogenesis of enteric infection by Campylobacter. Microbiology. 1997;143:5-21.

13. Murray PR, Rosenthal KS, Pfaller, MA. Medical microbiology. $5^{\text {th }}$ ed Philadelphia: Mosby Elsevier; 2005.

14. Rodrigues F, Calvino J, Alves AF, Lemos L. Diarreia aguda por Campylobacter spp. Acta Pediatr Port. 2006;37:91-4

15. Paiva M, Santos F, Amaral JMV. Gastrenterite Aguda. In: Amaral JV, editor. Tratado de Clínica Pediátrica. Lisboa: Abbott Lda; 2008. p. 532-6.

16. Bhutta ZA. Acute gastroenteritis in children. In: Kliegman RM, Stanton BF, Schor NF, Geme JW, Behrman RE, editors. Nelson Textbook of Pediatrics. Philadelphia: Elsevier Saunders; 2011. p. 1323-38.

17. Escobar C, Silva T, Costa B, Oliveira M, Correia P, Ferreira GC, et al. Gastroenterite aguda em crianças internadas na área de Lisboa. Acta Pediatr Port. 2013:44:148-55. 


\section{Gastroenterite Aguda por Campylobacter Spp: Casuística de uma Urgência Pediátrica}

Acta Med Port 2014:27:556-560

Publicado pela Acta Médica Portuguesa, a Revista Científica da Ordem dos Médicos

Av. Almirante Gago Coutinho, 151

1749-084 Lisboa, Portugal.

Tel: +351218428 215

E-mail: submissao@actamedicaportuguesa.com

www.actamedicaportuguesa.com

ISSN:0870-399X | e-ISSN: 1646-0758

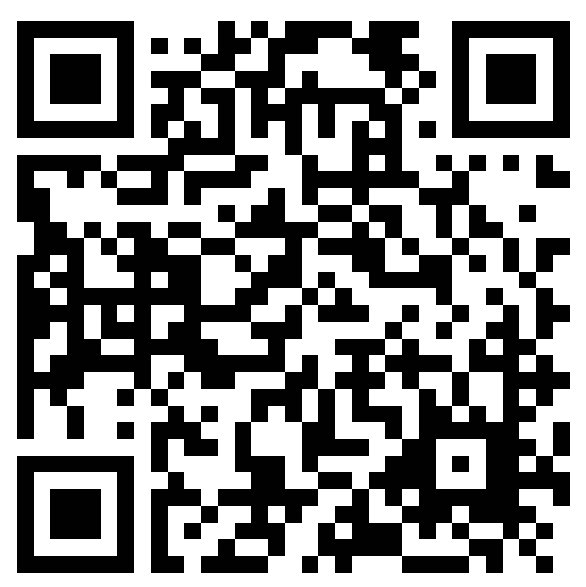

